\title{
Innovative circular path harvester for mechanical harvesting of irregular and large-canopy olive trees
}

\author{
Rafael R. Sola-Guirado*, Gregorio L. Blanco-Roldan, Sergio Castro-Garcia, \\ Francisco J. Castillo-Ruiz, Jesus A. Gil-Ribes \\ (Department of Rural Engineering, E.T.S.I. Agronomos y Montes, University of Cordoba, Campus de Rabanales, Ctra. \\ Nacional IV Km 396, Cordoba, Spain)
}

\begin{abstract}
The harvesting process of the olive tree is mainly performed by manual means, because traditional olive orchards (the main planting typology) are formed of irregular, large-canopy trees that are very difficult to harvest mechanically. For that reason, the cost of harvesting is very high, and it threatens the future of these plantations whose conversion to other more modern layouts is not always possible due to several limitations. The introduction of a harvester may represent the technological change that is the key factor for improved competitiveness. The main purpose of this work was to develop a harvester based on canopy shaker technology for work on irregular, large trees in a circular path. The design of the harvester was based on a determination of tree geometry, together with tree training. Field tests were used to determine machine-tree interaction, and to evaluate the removal, catch frame and driven systems. The proposed innovation allowed the fully mechanical harvest of previously planted trees with a removal efficiency of over $84 \%$, achieving an effective field capacity of $0.21 \mathrm{hm}^{2} / \mathrm{h}$. Although the results so far have been promising, further improvements are advisable in machine and tree adaptation.
\end{abstract}

Keywords: olive tree, olive fruit, canopy shaker, harvester, machinery design

DOI: $10.25165 /$ j.ijabe.20181103.3265

Citation: Rafael R. Sola-Guirado, Gregorio L. Blanco-Roldan, Sergio Castro-Garcia, F.J. Castillo-Ruiz, Jesus A. Gil-Ribes Innovative circular path harvester for mechanical harvesting of irregular and large-canopy olive trees. Int J Agric \& Biol Eng, 2018; 11(3): 86-93.

\section{Introduction}

Mechanical harvesting is one of the main activities that can be performed to reduce crop production costs or mitigate the dependency on labour ${ }^{[1]}$. In recent years, harvesting technologies for the mechanical fruit detachment process have been intensively studied, particularly for fruit trees such as oil olive trees whose production is destined for industrial transformation.

Initially, branch shakers and shaker combs facilitated fruit detachment by selecting the bearing branches without modifying the tree structure in crops that were traditionally manually harvested such as olive ${ }^{[2]}$, apricot ${ }^{[3]}$ or cherry trees ${ }^{[4]}$. Later, trunk shakers enabled detachment of the fruit from the whole tree after modifications had been made in tree structure, such as in olive $\mathrm{e}^{[5]}$ or almond trees ${ }^{[6]}$. A third development saw straddle harvesters used for integral harvesting in new, high-density olive orchards that had a different layout, pruned trees and a fully mechanised process, similar to that employed in vineyards ${ }^{[7]}$.

Received date: $2017-02-20 \quad$ Accepted date: $2017-12-13$

Biographies: Gregorio L. Blanco-Roldan, Associate Professor, research interests: agricultural mechanization, Email: ir3blrog@uco.es; Sergio Castro-Garcia, Associate Professor, research interests: agricultural mechanization, Email: scastro@uco.es; Francisco J. Castillo-Ruiz, PhD, Researcher, research interests: agricultural mechanization, Email: g62caruf@uco.es; Jesus A. Gil-Ribes, Professor, research interests: agricultural mechanization and conservation agriculture, Email: gilribes@uco.es. *Corresponding author: Rafael R. Sola-Guirado, PhD Researcher, research interests: agricultural mechanization and automation, Mailing Address: Department of Rural Engineering, E.T.S.I. Agronomos y Montes, Universidad de Córdoba, Campus de Rabanales, Ctra. Nacional IV Km 396, Cordoba, Spain. Tel: +34 957218523, Email: ir2sogur@uco.es.
In all of the above cases, mechanisation was carried out by adapting the orchard to the available harvesting technology, mainly in trees with homogeneous characteristics, planted closely in lines. However, sometimes it is not possible to replace existing orchards, which have important environmental and social components, with modern mechanised ones because of the low investment available, insufficient water supply or reduced farm size. This problem exists in several crops with an ancient tradition and culture where mechanisation is a key for production and profitability ${ }^{[8]}$. Olive growing in the Mediterranean basin is a clear example of the coexistence of all types of mechanical harvesting ${ }^{[9]}$, with irrigated narrow hedgerow orchards (more than 1500 trees $/ \mathrm{hm}^{2}$ ) adapted to grape harvesters, but also rain-fed traditional orchards (17300 trees $/ \mathrm{hm}^{2}$ ) harvested manually with sticks and nets.

The most widespread orchard category is the traditional one,

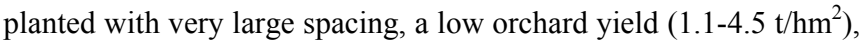
multi-trunk trained trees, and large-canopy trees ${ }^{[10]}$. Harvesting is the most expensive and difficult operation due to the complex tree structure involved, and current commercial systems rely on solutions that are highly conditioned by manual requirements ${ }^{[1]}$. There is no solution for the integral harvesting, which needs to be economically competitive in terms of time and cost, of the new high-density plantations. The introduction of a harvester may be a key factor in the solution of social and labour issues, as it could compensate for the lack of labour, make some operations less taxing, and reduce labour requirements, costs and harvesting time.

Lateral canopy shakers may prove suitable for the integral harvesting of traditional olive trees to simultaneously detach and collect fruit. The wide spacing between trees presents the opportunity to introduce an innovative harvesting process around 
the tree canopy ${ }^{[11]}$. However, all of the existing harvesters were designed for work in a row, normally with regular canopies. Consequently, the need exists to design a new harvester for a circular harvesting path around irregular canopies, in conjunction with trees that have been minimally trained beforehand to improve adaptation between machine and tree.

The main purpose of this paper is to develop a harvester for working in a circular path on irregular large-canopy trees. The proposed innovation requires research into tree geometry and behaviour in the shaking process, tree training, and machines developed in accordance with the resulting data. The field evaluation aims to demonstrate the viability of integral harvesting applied to traditional olive orchards. These results would offer new alternatives for the modernisation of the olive crop, enhancing crop sustainability and the cultural heritage that the crop represents. Moreover, the technology developed could be applied to other orchards and fruit trees facing similar problems of mechanisation.

\section{Materials and methods}

\subsection{Geometric determination of the trees to be harvested}

In order to meet harvester design requirements, it is necessary to obtain tree features. The geometric description of trees was carried out in three different, representative, traditional olive orchards suitable for mechanical harvesting. These three orchards represent $52 \%$ of the area devoted to the cultivation of olives in Spain ${ }^{[10]}$. Spain is the world's top olive oil producer and exporter, with $2.6 \mathrm{Mhm}^{2}$ of total area planted ${ }^{[12]}$. The representative orchards are located in the provinces of Cordoba and Jaen, and the trees are Hojiblanca and Picual cultivars, which represent over $43 \%$ of Spain's total surface area for olive tree culture ${ }^{[13]}$. In addition, fruit yields over two 'on' harvesting seasons were obtained to size the harvester's conveyors and storage system.

Tree geometries were studied from two digital images of 48 trees in each orchard taken at ground level and from one orthoimage obtained with a DJI S800 and Wookong-M unmanned aerial system (UAS), (DJI, Shenzhen, China) (Figure 1). Ground images were acquired using a Sony Nex7 digital camera (Sony, Tokio, Japan) with an aperture of 3.6, a focal length of $18 \mathrm{~mm}$ and an ISO velocity index of 100, between 12:00-14:00, at $1.8 \mathrm{~m}$ above the ground. A white plastic background was set behind the trees to aid image processing in their vertical profiles. Aerial images enabled the generation of orthoimages from the orchards with Pix4D software (Pix4D, Lausanne, Switzerland), using the images acquired with the same camera located on the UAS, which was operated using waypoint navigation guidance for automatic image acquisition and synchronisation. The flight plan was set at a height of $90 \mathrm{~m}$ above ground and a speed of $8 \mathrm{~m} / \mathrm{s}$, setting a longitudinal and transversal overlap of $85 \%$ and $70 \%$, respectively.

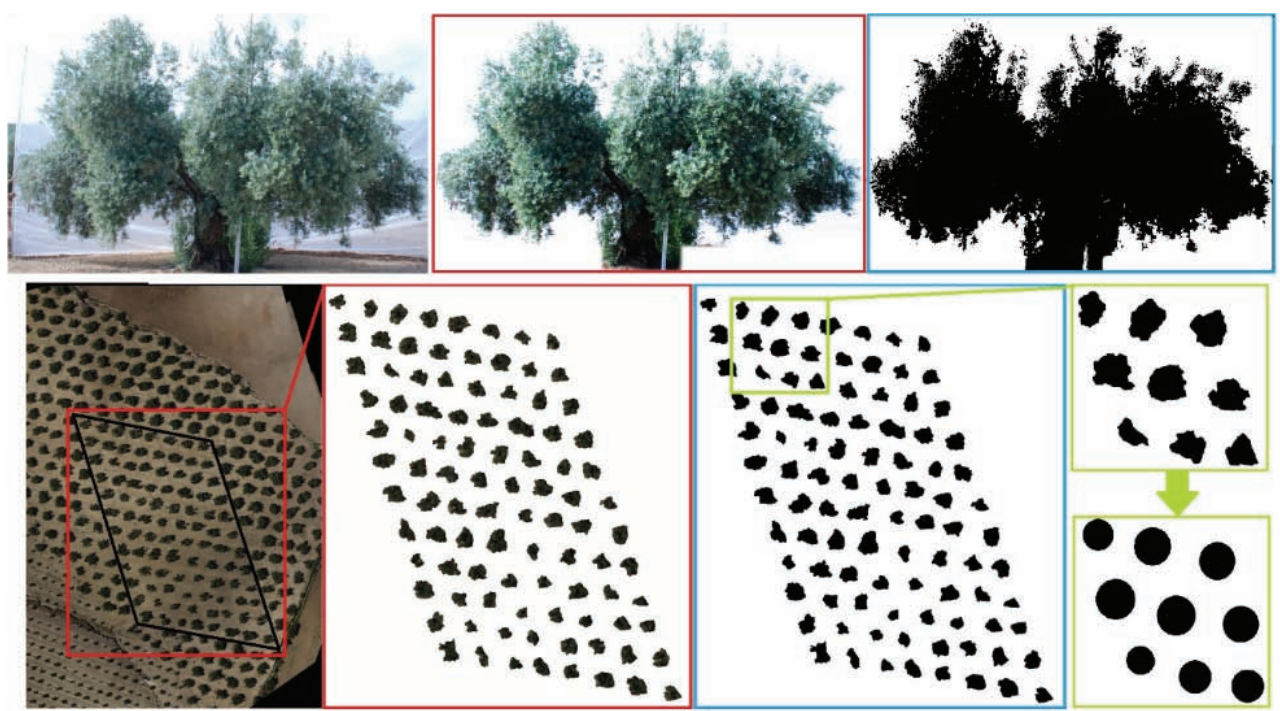

Figure 1 Tree images from ground (top) and from a UAS (bottom) used to determine the tree geometric features for the design of a harvester with canopy shaker

In both cases, image processing was performed manually by an expert trained for this purpose using ImageJ v1.50i (National Institutes of Health, Maryland, USA). Images were transformed into greyscale to create a monochromatic image for digital image processing. Two threshold levels were used in the greyscale image to separate the tree contour. Finally, a binary image was obtained of each particle, scaling and converting pixels to $\mathrm{m}^{2}$ for particle analysis ${ }^{[14]}$. Images at ground level were analysed to determine tree pattern contour according to their vertical profiles, and to size the harvester's removal system. Images at aerial level were used to size the harvester's catch frame. Aerial images were also used for adjusting individual tree areas to circles by Image $J$ in order to set the circular path for harvesting and to size the driven system.

\subsection{Geometric determination of the machine design}

The design of an effective harvester should satisfy several requirements according to tree and orchard characteristics, but also meet conditions for road transport. The machine has to be broken down into several components, each designed with its own method, but without losing the relationship and connections with the whole $\left.{ }^{[15]}: 1\right)$ a removal system based on canopy shaker heads for detaching fruit, 2) a catch frame system to receive and manage fruit, with a set of plates to maintain correct contact with trunks, and 3) a driven system that supports all components and allows movement in a correct harvesting path around each tree.

In general terms, the canopy shaker must perform an effective fruit-detachment process with the right motion, amplitude and frequency. It must be possible to simultaneously collect the detached fruits. The driven system must possess adequate manoeuvrability for harvesting around the tree. Moreover, the harvester must allow a continuous shaking process, avoiding severe damage while maintaining the closest possible contact with the tree canopy. Specifically:

1) The removal system must be composed of several shaker 
heads formed of drums with rods that approach independently to provide a better fit to tree canopy irregularities in vertical profiles (Figure 2, purple elements). However, the existing mechanisms that achieve this vibration pattern are based on a single crankshaft that moves all of the shaker heads, so these mechanisms were not valid because each shaker head needs to operate independently. On the other hand, the mechanism must be designed to perform a vibration pattern on bearing branches similar to the one studied by Sola-Guirado et al. ${ }^{[2]}$ and by Sola-Guirado et al. ${ }^{[17]}$. The suitable motion for detaching olives with mechanical rod beating requires a frequency of $5 \mathrm{~Hz}, 0.16 \mathrm{~m}$ of amplitude, and a $0.8 \mathrm{~km} / \mathrm{h}$ ground speed with RMS acceleration values of around $180 \mathrm{~m} / \mathrm{s}^{2}$ but also the capacity to perform short, high peaks of acceleration close to $1 \mathrm{~km} \mathrm{~s}^{-2}$. Bearing in mind these specifications, the mechanism developed by Blanco-Roldan et al. ${ }^{[16]}$ was redesigned, manufactured and tested on olive trees with different configurations to achieve the most similar vibration pattern (Figure 5). The variables tested were: mechanism and motion of the rods (linear crossed and rotational crossed), rods (plastic with fiberglass and steel F112), and turning resistance of the drums (free and braked).

2) The catch frame needs to cover the projected area that the rods could reach (Figure 2, indicated with blue lines) in order to collect the detached fruit ${ }^{[17]}$. The harvested fruit must be transported by a set of conveyors and cleaned before storage in a big bag. In this way, once full, the bags can be left in the field ready for collection. This would make the process continuous and eliminate the need to stop harvesting to wait for the hopper bins to be emptied of harvested fruit by another machine, such as a tractor.

3) The driven system (Figure 2, grey elements). In order to develop a feasible prototype, and based on the assumption that all farms have a tractor to perform agricultural operations, the harvester was designed to be trailered and powered by a tractor. Finally, in this pre-design it was deemed advisable to set two axles with two wheels on either side of the fruit collection area (Figure 2, blue rectangle). The long distance between the axles suggested the incorporation of a system to adapt to the peculiarities of the terrain.

Each component was designed according to tree features obtained from ground and aerial images, following the order shown in Figure 2. The three main systems of the harvester were redesigned and adapted into a whole machine using Solidwork (Dassault Systemes, Massachusetts, USA).

1) The removal system height (A) was determined by the tree height with a minimum position above the ground (B) according to tree skirt height.

2) The rod length (C) was sized to penetrate the tree canopy.

3) The maximum approach capacity to the tree canopy by the heads (D) was calculated using the distance from the vertical contour to the most exterior edge of the tree silhouette.

4) The catch frame width $(E+F)$ covered the removal system area and its approach capacity to the canopy.

5) The catch frame had long plates (F) that folded to seal any gaps in the event of collision with trunks in the circular path.

6) The catch frame length $(G)$ covered the removal system area without limiting the harvester's turning radius, which is correlated with the separation distance of the axles $(\mathrm{H})$ and wheel distance (I). The wheel distance (I) was fixed at $2.55 \mathrm{~m}$ due to Spanish transport regulations.

7) The mean turning radius ( $\mathrm{J}$ ) that the driven system had to attain to be as close as possible to the tree canopy was calculated with the fitting circles obtained from aerial contours.

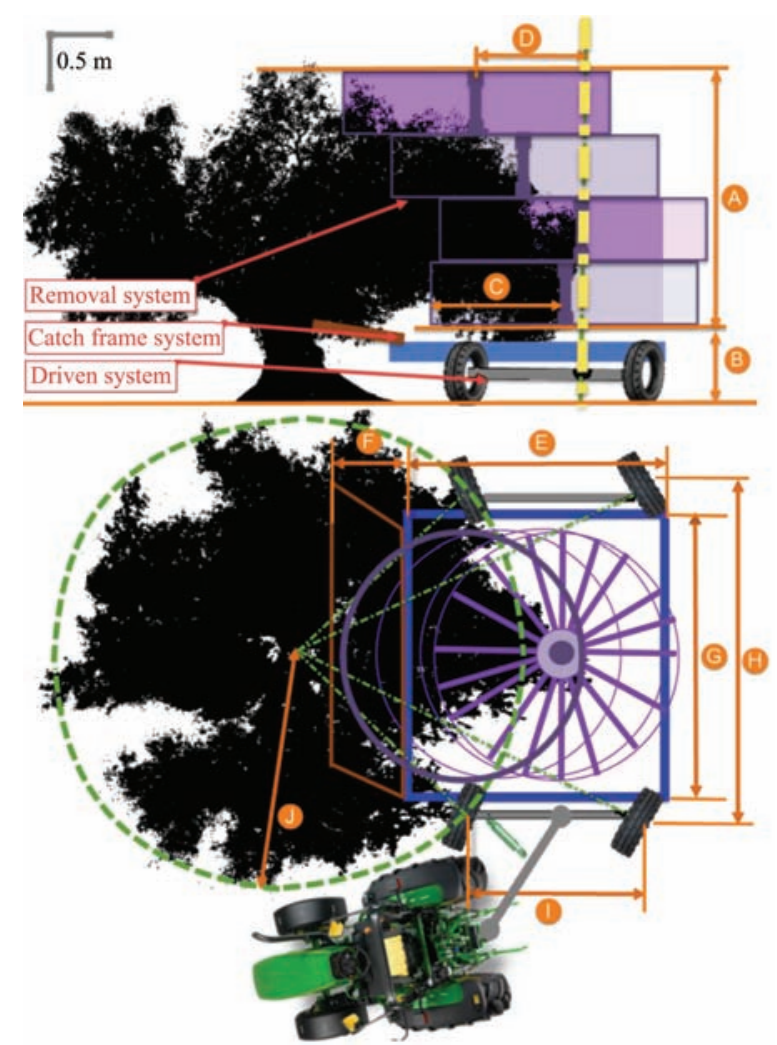

Note: The machine parameters are: removal system height (A) and positioning above the ground (B); rod length (C); shaker head approach capacity (D); catch frame width $(\mathrm{E})$; catch plate length $(\mathrm{F})$; catch frame length $(\mathrm{G})$; axle distance $(\mathrm{H})$ wheel distance (I) and turning radius $(\mathrm{J})$.

Figure 2 Conceptual design to size the harvester to olive tree features in a circular harvesting path

\subsection{Harvester-tree interaction}

The use of a new harvester requires previous tree training in order to be able to use the machine. Pruning was performed on a completely randomised block design of 64 trees in each test orchard. Two different pruning treatments were applied from 2012 to 2015: current pruning, normally targeted at harvesting with trunk shaker and manually aided systems, and adapted pruning targeted at harvesting with a canopy shaker. Pruning for a canopy shaker (Figure 3) was developed with the aim of adapting the tree structure in order to obtain high harvesting efficiency in traditional olive trees. Inner branches were removed, because the canopy shaker rods could not reach the canopy central volume, while outer bearing branches were kept. Outer branches that hindered continuous canopy shaker work around the tree canopy were also removed to procure a round canopy perimeter. Renewal pruning was only used for secondary limbs when it enhanced a circular path around the tree canopy. Lower branches that could hinder catch frame performance were also removed to facilitate fruit detachment, catching and management. Tree height was limited to $3.5 \mathrm{~m}$.

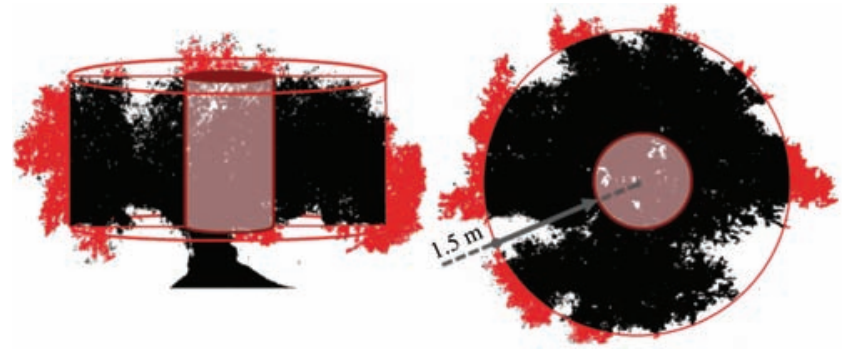

Note: Zones highlighted in red indicate the areas to limb removal.

Figure 3 Pruning for canopy shaker performed on traditional olive trees 


\subsection{Harvester evaluation}

Harvesting tests were carried out in olive (Olea europaea L.) orchards in Cordoba $\left(37.717^{\circ} \mathrm{N}, 4.806^{\circ} \mathrm{W}\right)$ and Jaen $\left(37.738^{\circ} \mathrm{N}\right.$, $\left.4.145^{\circ} \mathrm{W}\right)$ planted more than one century ago at $70-80$ trees $/ \mathrm{hm}^{2}$ with Hojiblanca and Picual cultivars respectively. All of the trees were healthy and in good phytosanitary condition. The mean fruit detachment force (FDF) measured during tests was $3.65 \mathrm{~N}$ and $2.25 \mathrm{~N}$ in Hojiblanca and Picual cultivars respectively. The harvester followed a circular path around trees, keeping the shaking heads as close as possible to the canopy contour. At the same time, a trunk shaker mounted on one tractor, with three people for canopy beating with poles and another six people to move the nets (the most common method in traditional olive harvesting), harvested another 30 trees for comparison of results.

Four parameters were determined to evaluate machine-tree interaction:

1) Fruit removal efficiency: the relation between fruit detached by canopy shaker and total canopy fruit production. The fruit remaining in trees after harvesting was classified according to fruit in the inner and the outer canopy $(1.5 \mathrm{~m}$ from the exterior, Figure 3). Thus the calculations were made for outer removal efficiency, fruit suitable to harvest with the canopy shaker, and total removal efficiency, taking into account the whole tree.

2) Catch frame efficiency: the relation between fruit intercepted by the catch frame and fruit detached by the canopy shaker.

3) Harvester efficiency: the relation between fruit intercepted by the catch frame and the outer (outer) or total canopy fruit production (total).

4) Debris production: the weight of leaves, shoots and small branches as a measurement of tree damage due to the harvesting process.

\section{Results and discussion}

\subsection{Geometric determination of the trees to be harvested}

The geometric description of trees was necessary for correct adaptation of the harvester design to the trees and to the harvest path. Photogrammetry techniques provided valuable information to characterise orchards from ground and aerial images, although it is possible to measure trees using other manual or electronic methods ${ }^{[18]}$. Several tree and orchard features obtained from the analysed images are shown in Table 1.

Table 1 Tree and orchard features of representative traditional orchards obtained from ground and aerial images $(n=144)$

\begin{tabular}{lc}
\multicolumn{1}{c}{ Traditional orchard trees } & Mean \pm Standard deviation \\
\hline Tree height $/ \mathrm{m}$ & $3.89 \pm 0.38$ \\
Skirt height $/ \mathrm{m}$ & $0.55 \pm 0.12$ \\
Number of trunks per tree & $2.6 \pm 0.3$ \\
Tree spacing $/ \mathrm{m}$ & $10.64 \pm 1.34$ \\
Major canopy diameter $/ \mathrm{m}$ & $6.76 \pm 1.48$ \\
Minor canopy diameter $/ \mathrm{m}$ & $5.96 \pm 1.16$ \\
Fitting circle diameter to canopy contour $/ \mathrm{m}$ & $6.21 \pm 0.82$ \\
Fruit yield $(2013-14$ season $) / \mathrm{kg} \cdot$ tree $^{-1}$ & $38-156$ \\
Fruit yield $(2014-15$ season $) / \mathrm{kg} \cdot$ tree $^{-1}$ & $37-132$ \\
\hline
\end{tabular}

Large differences were found in tree vertical contours (Figure 4) between the distances from the outermost points (Figure 2, yellow line) to the tree contour.

The removal system, limited to $2.8 \mathrm{~m}$ according to previous design restrictions between 1.0 and $3.8 \mathrm{~m}$ above ground, was split into several independent shaker heads to better fit the tree's vertical contour. Based on the shaker head design obtained by Blanco-Roldan et al. ${ }^{[16]}$, with rods at a distance of $0.4 \mathrm{~m}$, four heads were used for shaking this canopy volume. Each shaker head can approach the tree up to $1 \mathrm{~m}$ from its minimum position, which corresponds to the mean maximum difference in distances from the most external point of the tree contour and which is between the heights of 3.0 and $3.5 \mathrm{~m}(1.05 \mathrm{~m})$ (Figure 4$)$. In this regard, for the harvester to function well it is advisable to perform pruning to eliminate irregular branches and achieve the most regular vertical contour possible.

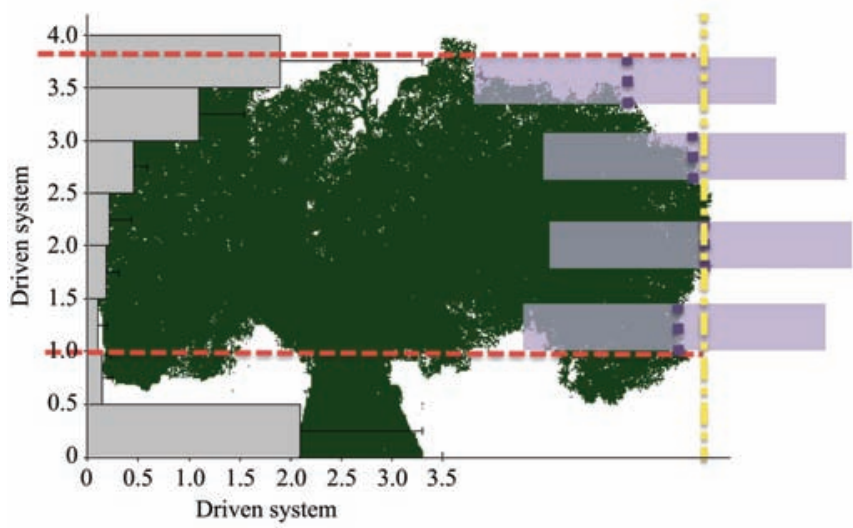

Figure 4 Horizontal distances between the most exterior point

(Figure 2, yellow line), and contour in tree vertical contours according to different height zones

\subsection{Geometric determination of the machine design}

The harvester height (Figure 2, A+B) was $3.7 \mathrm{~m}$ and related with mean tree height because, although tree production at the top is less than $20 \%$, it gives a high oil yield ${ }^{[19]}$. Moreover, this is well within the limits of legal restrictions (maximum $4.5 \mathrm{~m}$ ). The lower branches of trees are less than $1 \mathrm{~m}$ above the ground and concentrate more than $25 \%$ of tree production. So the first shaker head (Figure 2, B) was situated $1 \mathrm{~m}$ above the ground due to the flexibility of these branches and to facilitate catch frame incorporation. In this regard, to facilitate the harvester's work it is advisable to prune the tree to elevate skirt height and to control tree height.

Tree canopies had a large mean diameter that made it impossible to shake the whole canopy volume because of the previous design restriction. The mean canopy volume suitable for harvesting was about $2.18 \mathrm{~m}$ of penetration from the exterior. This is because tree mean radius was $3.18 \mathrm{~m}$, but within the inner canopy volume there is an area $0.5 \mathrm{~m}$ from the centre of the tree that produces both very low quantity (less than $10 \%$ ) and oil yield ${ }^{[19]}$. On the other hand, the outer tree growth produces flexible branches that allow compression of the canopy by the removal system without major debris ${ }^{[20]}$, about $0.5 \mathrm{~m}$ from the canopy exterior edge according to previous experience. At this point it would only be necessary to penetrate $1.68 \mathrm{~m}$ from the exterior as the shaking process detaches fruit because rods contact directly with the branches, but there is also an acceleration transmission further to this contact influenced by the tree architecture ${ }^{[21]}$. Finally, rod length (Figure 2, C) was fixed at $1.5 \mathrm{~m}$ to reach at least $70 \%$ of suitable canopy volume ( $2.18 \mathrm{~m}$ in diameter), with the remaining volume agitated by the vibration performed on the outer branches. Rod section and stiffness were selected to perform adequate shaking without rod deformation. In this regard, to facilitate the harvester's work it is advisable to train trees, so that $g$ the yield of 
outer branches increases and the inner bearing branches are eliminated.

Each shaker head can approach the tree up to $1 \mathrm{~m}$ from its minimum position, which corresponds to the mean maximum difference in distances from the most external point of the tree contour, and which is between the heights of 3.0 and $3.5 \mathrm{~m}(1.05 \mathrm{~m})$ (Figure 4). To this effect, for the harvester to function it is advisable to perform pruning to eliminate irregular branches and achieve the most regular vertical contour possible.

Several empirical results may be extracted from the test carried out with the prototype shown in Figure 5. A linear mechanism has better interaction with branches and causes less debris than the rotational mechanism but is less robust and requires a complex lubrication system to avoid overheating. Using braked drums, the rods' impact with branches is higher than when using free turning drums, but rods drag the branches and do not shake them adequately. Plastic rods produce lower debris in comparison with metallic ones, but the impact with branches is also lower. So, the best configuration was a rotational mechanism based on eccentric masses that move drums with free turning, metallic rods.
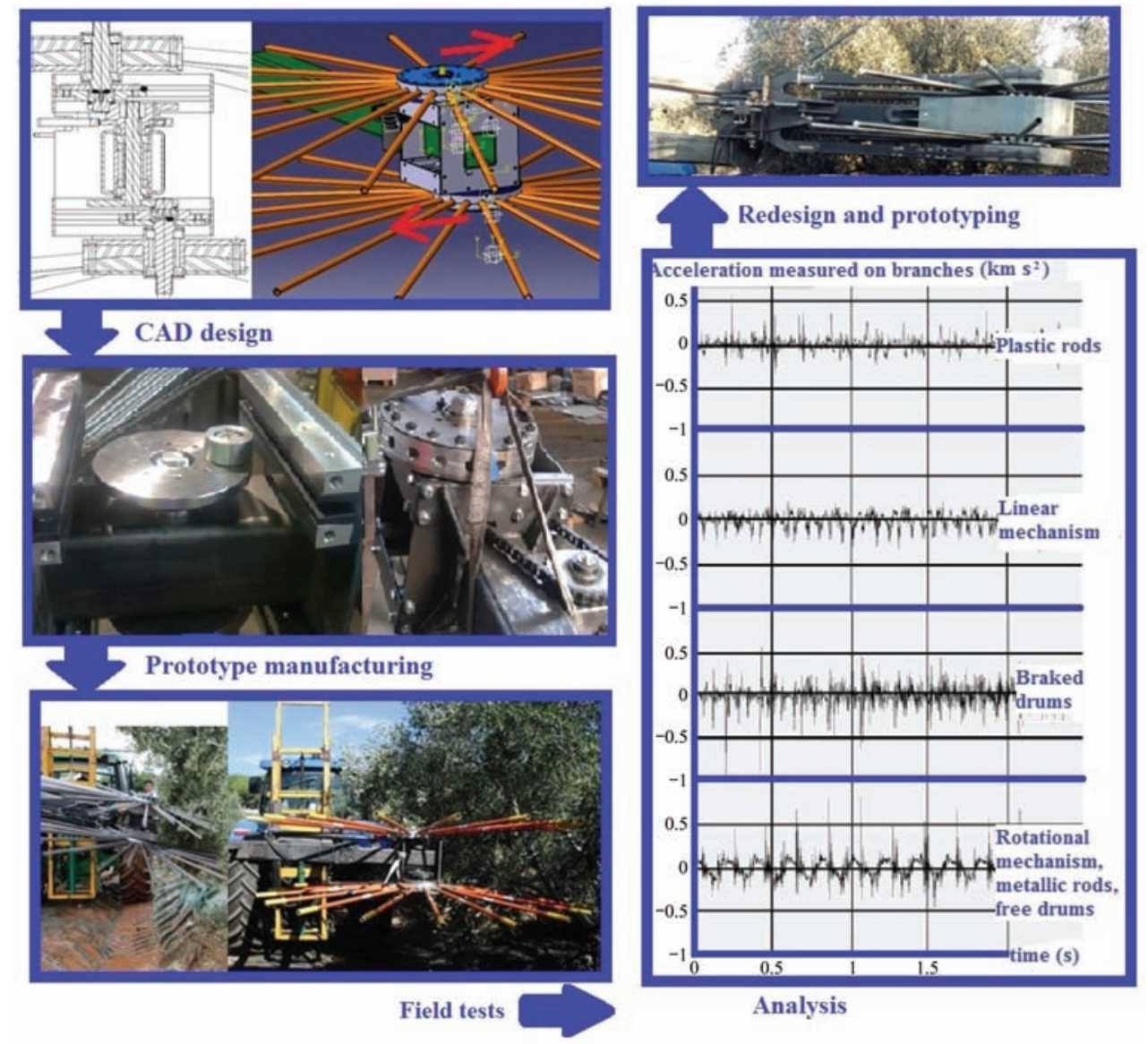

Figure 5 Process carried out to develop the removal system based on shaker heads

Aerial images showed a high variation between tree contours. These tree contours fit circles with diameters of $(6.21 \pm 0.82) \mathrm{m}$. This suggests that tractor and harvester perform a mean turning radius (Figure 2, J) of $3.1 \mathrm{~m}$ for the circular harvesting path. The original contour circularity shape factor, as a function of perimeter and area, was 0.66 (the circularity of a circle is 1 and much less than 1 is a star). This value indicated the irregularities of contours, so it suggested complementing the tractor's circular path with an alternative movement to correct the path. This is why a controlled pull bar was set between the tractor and the harvester that allowed displacement of the harvester $0.8 \mathrm{~m}$ from the tractor path, according to the calculated mean differences between major and minor tree diameters (Table 1). This path was performed thanks to the pull bar and two self-turning wheels on the front axle together with two steering wheels on the rear axle, all controlled by an operator. Each axle was able to simultaneously pivot $12^{\circ}$ to each side to better fit the ground, with manual or automatic levelling using an inclinometer sensor. In this regard, to facilitate harvester functioning it is advisable to prune tree aerial contours so that they conform to more regular geometries similar to a circle.

Aerial imagery determined a mean spacing of $10.64 \mathrm{~m}$ between trees and a mean tree major diameter of $6.76 \mathrm{~m}$. The distance between tree canopies (about $3.9 \mathrm{~m}$ ) was sufficient space to move around trees without breaking branches because the width of the harvester (Figure 2, E) was fixed at $3 \mathrm{~m}$ due to legal restrictions on road transport, and according to rod lengths $(1.5+1.5 \mathrm{~m})$. Moreover, the catch frame had a folding structure $1 \mathrm{~m}$ in width (Figure 2, F) for the collection of fruit that might be detached by the approach of the heads. This structure was composed of long catch plates that deflected fallen fruit to the conveyors and allowed a correct trunk seal because, thanks to a spring mechanism, the plates pivot as they collide with the trunk and return to the initial position once there is no obstruction. The catch frame length (Figure 2, G) was limited to $3.2 \mathrm{~m}$ due to the conditions of the turning radius and the distance between wheels.

Detached fruit was transported on several conveyors to one side of the harvester where debris was separated (Figure 6). Then, the fruit passed to another conveyor that carried it to the rear, where it was stored in a big bag. A maximum tree yield of $156 \mathrm{~kg}$ (Table 1), a mean harvest efficiency of $80 \%$, and a mean tree harvesting time of $210 \mathrm{~s}$ indicated a mean fruit flow of $0.6 \mathrm{~kg} / \mathrm{s}$ for the adjustment of conveyor velocity. 
The machine components (Figure 6) were mounted on a chassis which had a vertical column where the cantilevers that supported the shaker heads were held. The mechanisms were powered by a hydraulic power unit located in the tractor. Two people were required: one person to drive the tractor and direct the harvester path and another to control the shaker heads approaching the tree. More details are shown in patent ES 2560353.
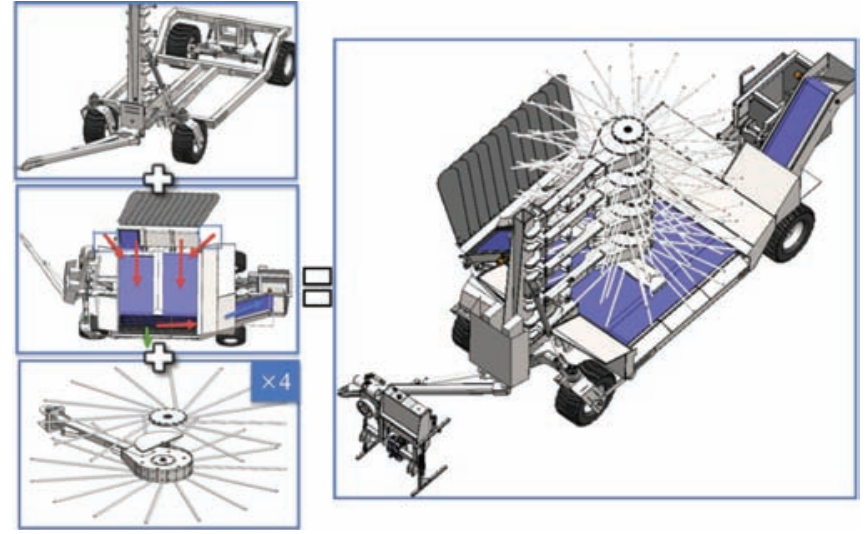

Figure 6 Design of components (driven system, catch frame and canopy shaker head) and integration in a harvester

\subsection{Harvester-tree interaction}

The fresh weight of pruning was significantly ( $p<0.05$; $T$-test, higher for adapted pruning than for the current pruning method, although this factor was highly conditioned by the canopy volume of each tree. The accumulated weight for the four years of testing was 70.1-111.2 kg/tree for the current method, and 125.7$139.9 \mathrm{~kg} /$ tree for the adapted method. Tree yield did not provide significant differences $(p<0.05 ; T$-test, $)$ between pruning treatments for the same cultivar and harvesting season, although the adapted system was slightly lower (about $3 \%$ of tree yield), considering that in adapted pruning the inner branches were cut more intensely because trees were not adapted to canopy shakers. The lack of differences in yield makes it recommendable to perform adapted pruning to facilitate harvester interaction with trees.

\subsection{Harvester evaluation}

The field tests results (Figure 7) related to harvester-tree interaction are shown in Table 2. The harvester gave some promising results compared to the available methods in traditional harvesting, with a mean fruit removal efficiency of $79 \%$ and $89 \%$ for trees with and without adaptation, respectively. No significant differences were found between varieties for either of the pruning systems $(T$-test, $p<0.05)$. There were no significant differences in FDF with regard to mean removal efficiency ( $T$-test, $p<0.05$ ), which shows the harvester's suitability for reaching high removal values in early or late season or with different maturity status and varieties. On the contrary, the relation between FDF and detachment is very important in harvesting with the trunk shaker ${ }^{[22]}$. The use of abscission agents for reducing FDF values is highly recommended in other crops, like citrus ${ }^{[23]}$, although it is not compulsory for achieving high removal efficiency when complementary rod beating is used or with mechanical canopy shakers $^{[24]}$.

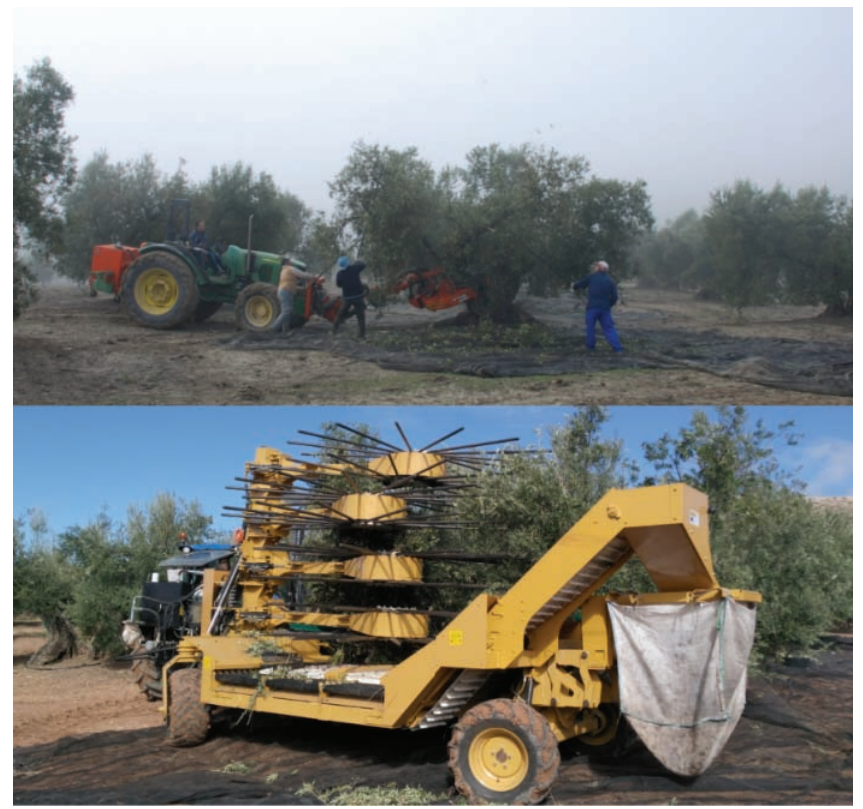

Figure 7 Most common method (trunk shaker and manual canopy beating) used for harvesting (top) and new method (canopy shaker around the tree) (bottom)

Table 2 Evaluation of parameters performed by the harvester in a circular path on traditional olive orchards. Values shown mean \pm standard deviation

\begin{tabular}{|c|c|c|c|c|c|c|c|c|}
\hline \multirow{2}{*}{ Cultivar } & \multirow{2}{*}{ Pruning } & \multirow{2}{*}{$\mathrm{N}$} & \multicolumn{2}{|c|}{ Fruit removal efficiency $/ \%{ }^{\mathrm{a}}$} & \multirow{2}{*}{$\begin{array}{l}\text { Catch frame } \\
\text { efficiency } / \% \text { b }\end{array}$} & \multicolumn{2}{|c|}{ Harvester efficiency $/ \%{ }^{c}$} & \multirow{2}{*}{$\begin{array}{c}\text { Debris } \\
\text { production } / \mathrm{kg} \cdot \text { tree }^{-1 \mathrm{~d}}\end{array}$} \\
\hline & & & Outer & Global & & Outer & Global & \\
\hline \multirow{2}{*}{ Hojiblanca* } & Current & 29 & $86 \pm 11$ & $74 \pm 19$ & $78 \pm 7$ & $69 \pm 13$ & $58 \pm 14$ & $4.9 \pm 2$ \\
\hline & Adapted & 31 & $89 \pm 12$ & $80 \pm 14$ & $83 \pm 12$ & $75 \pm 7$ & $69 \pm 8$ & $4.2 \pm 2$ \\
\hline \multirow{2}{*}{ Picual* } & Current & 30 & $96 \pm 4$ & $83 \pm 10$ & $76 \pm 9$ & $74 \pm 11$ & $62 \pm 11$ & $7.8 \pm 5$ \\
\hline & Adapted & 29 & $97 \pm 1$ & $88 \pm 11$ & $78 \pm 9$ & $77 \pm 10$ & $68 \pm 10$ & $6.9 \pm 4$ \\
\hline All* & Adapted & 60 & $93 \pm 8$ & $84 \pm 17$ & $80 \pm 10$ & $76 \pm 16$ & $69 \pm 12$ & $5.2 \pm 4$ \\
\hline \multirow{2}{*}{ Picual** } & Current & 30 & \multicolumn{2}{|c|}{$98.0 \pm 1.0$} & - & \multicolumn{2}{|c|}{-} & $7.2 \pm 4.6$ \\
\hline & Adapted & 30 & \multicolumn{2}{|c|}{$98.6 \pm 1.1$} & - & \multicolumn{2}{|c|}{ - } & $6.2 \pm 4.9$ \\
\hline
\end{tabular}

Note: *Harvesting performed with canopy shaker; ${ }^{*}$ Harvesting performed with trunk shaker and manual beating; ${ }^{\text {a }}$ Fruit removal efficiency $=$ detached fruit by the harvester / total canopy fruit production; ${ }^{\mathrm{b}}$ Catch frame efficiency $=$ fruit intercepted by the catch frame $/$ detached fruit by the harvester; ${ }^{\mathrm{c}}$ Harvester efficiency $=$ fruit intercepted by the catch frame / total canopy fruit production; ${ }^{\mathrm{d}}$ Debris production $=$ leaves, shoots and small branches detached during harvesting process.

Fruit location in tree canopies was determinant to achieve high fruit removal efficiency values in both varieties, although there were no significant differences between pruning systems ( $T$-test, $p<0.05$ ), mainly due to the high dispersion values in fruit. Nonetheless, pruning adapted to the harvester achieved a reduction in inner production and an improvement in harvester-tree contour contact. On the other hand, mean removal efficiency was higher with no significant differences in tree production ( $T$-test, $p<0.05$ ). Likewise, outer removal efficiency had an excellent result of detached fruit in the canopy volume where rods were in direct 
contact; however, most non-detached fruit was located here, likely due to the removal system's dimensions (1.0-3.8 $\mathrm{m}$ above the ground). A longer period of tree training is necessary to progressively adapt the tree to the harvester, as has been performed in high density orchards over 6 years ${ }^{[25]}$ or in traditional ones up to eight years ${ }^{[26]}$.

Developing a circular path harvester for irregular trees has shown that one of the greatest difficulties is catching the detached fruit. The mean catch efficiency values (77\% and $80 \%)$ show the need for improvements in the catch frame system in comparison with other commercial harvesters that collect more than $90 \%$ working in a line and on both halves of trees ${ }^{[7,24]}$. Most catch frame losses were located in front of the harvester near the tree due to the incorporation of the self-turning wheel to reduce the catch frame area in this zone. This explains why the losses were higher in trees where FDF was lower due to the higher concentration of detached fruit in this area within the first few seconds of vibration $^{[27]}$. As a consequence, the catch frame size design must be in accordance with removal system size and have no chassis limitations.

Debris production showed no significant differences between the trunk shaker and the canopy shaker $(T$-test, $p<0.05)$. Results were in line with those produced by other available harvesting systems of $2 \%-6 \%{ }^{[2]}$. Most large debris were due to branches broken by the shaker during the harvesting path, mainly in trees with extremely irregular canopies. Tree training should reduce debris production as canopies would be more rounded. Future improvements could reduce debris by the addition of a padding material to the shaker head and rods.

The mean time for harvesting was about $210 \pm 22 \mathrm{~s} /$ tree (mean $\pm \mathrm{sd}$ ), so the work capacity was $(0.22 \pm 0.02) \mathrm{hm}^{2} / \mathrm{h}$ in an $80 \mathrm{tree} / \mathrm{hm}^{2}$ orchard, with two workers. Results are lower than other lateral canopy shakers, with an effective field capacity between 0.15 and $0.83 \mathrm{hm}^{2} / \mathrm{h}^{[28]}$. Further improvements could be incorporated to enhance harvester manoeuvrability by a self-propelled system that would allow an increase in ground speed. On the other hand, the trunk shaker had a work capacity of $(0.29 \pm 0.02) \mathrm{hm}^{2} / \mathrm{h}$, which made it the most competitive method of the available methods used. However, the main restriction of this method is the labour requirement for manual canopy beating, net movement and fruit loading, which increase harvesting costs.

\section{Conclusions}

The introduction of the innovative circular path harvester presented in this paper has shown promising results. It is possible to achieve a mean removal efficiency of $79 \%-84 \%$ with debris similar to that of the available methods. It is highly advisable to perform longer-term tree training to improve the general efficiency of the harvester. The modernisation process in this traditional sector of agriculture will require a great effort and the simultaneous input of researchers, machinery manufacturers and farmers; it should also be taken into account that traditional olive growing is one of the world's oldest tree crops and is immersed in a culture that is resistant to change. The methodology set forth in this paper can also be used in the development of new harvesters for other crops with similar mechanisation requirements. Moreover, other issues such as slopes, machine weight and manufacturing cost must be considered for advances in the mechanical harvesting of the crop.

\section{Acknowledgements}

The authors gratefully acknowledge financial support from the Spanish Ministry of Economy and Competitiveness (PCP Mecaolivar), and the Spanish Olive Oil Interprofessional Organisation. The authors would also like to express their gratitude for the collaboration of the machinery company, Moresil S.L.

\section{[References]}

[1] Gil-Ribes J A, Ferguson L, Castro-Garcia S, Blanco-Rodán G L. How agricultural engineers develop mechanical harvesters: The university perspective. HortTechnology, 2014; 24(3): 270-273.

[2] Sola-Guirado R R, Castro-García S, Blanco-Roldán G L, Jiménez-Jiménez F, Castillo-Ruiz F J, Gil-Ribes J A. Traditional olive tree response to oil olive harvesting technologies. Biosystem Engineering, 2014; 118: 186-193.

[3] Erdoğan D, Güner M, Dursun E, Gezer İ. Mechanical harvesting of apricots. Biosystems Engineering, 2003; 85(1): 19-28.

[4] He L, Zhou J, Du X, Chen D, Zhang Q, Karkee M. Energy efficacy analysis of a mechanical shaker in sweet cherry harvesting. Biosystems Engineering, 2013; 116(4): 309-315.

[5] Jimenez-Jimenez F, Blanco-Roldan G L, Castillo-Ruiz F J, Castro-Garcia S, Sola-Guirado R, Gil-Ribes J A. Table olives mechanical harvesting with trunk shakers: Orchard adaption and machine improvements. Chemical Engineering Transactions, 2015; 44: 271-276.

[6] Abdel-Fattah H M, Shackel K A, Slaughter D C. Methodology for determining almond shaker displacement and frequency. Applied Engineering in Agriculture, 2003; 19(2): 141.

[7] Ravetti L, Robb S. Continuous mechanical harvesting in modern Australian olive growing systems. Advances in Horticultural Science, 2010; 24(1): 71-77.

[8] Ou Y G, Wegener M, Yang D T, Liu Q T, Zheng D K, Wang M M, et al. Mechanization technology: The key to sugarcane production in China. Int J Agric \& Biol Eng, 2013; 6(1): 1-27.

[9] Vossen P. Olive oil: History, production, and characteristics of the world's classic oils. HortScience, 2007; 42(5): 1093-1100.

[10] AEMO, Asociación Española de Municipios del Olivo. Aproximación a los costes de los distintos sistemas del cultivo del olivo. 2012. http://www.aemo.es. (in Spanish). Accessed on [2013-05-22]

[11] Sola-Guirado R R, Ceular-Ortiz D, Gil-Ribes J A. Automated system for real time tree canopy contact with canopy shakers. Computers and Electronics in Agriculture, 2017; 143: 139-148.

[12] IOC. 2012. http://www.internationaloliveoil.org/estaticos/view/ 136-country-profiles/ Accessed on [2016-12-28]

[13] Barranco D, Rallo L. Olive cultivars in Spain. Horttechnology, 2000; 10: $107-110$.

[14] Igathinathane C, Pordesimo L O, Columbus E P, Batchelor W D, Methuku S R. Shape identification and particles size distribution from basic shape parameters using ImageJ. Computers and Electronics in Agriculture, 2008; 63(2): 168-182.

[15] Pahl G, Beitz W, Feldhusen J, Grote K H. Engineering design: a systematic approach, 2007; Springer-Verlag, London, UK. 617 p.

[16] Blanco-Roldán G, Castillo-Ruiz F, Sola-Guirado R R, Jiménez-Jiménez F, Castro-García S, Agüera-Vega J, Gil-Ribes J A. Olive harvesting by canopy shaker. In Proceedings of the International Conference of Agricultrual Engineering AgEng, 2014; Zurich, (Switzerland), July 6-10. pp. $1-8$

[17] Sola-Guirado R R, Jiménez-Jiménez F, Blanco-Roldán G L, Castro-García S, Castillo-Ruiz F J, Gil-Ribes J A. Vibration parameters assessment to develop a continuous lateral canopy shaker for mechanical harvesting of traditional olive trees Spanish Journal Agricultural Research, 2016; 14(2); e0204.

[18] Rosell J R, Sanz R. A review of methods and applications of the geometric characterization of tree crops in agriculture activities. Computers and Electronics in Agriculture, 2011; 81: 124-141.

[19] Castillo-Ruiz F J, Jiménez-Jiménez F, Blanco-Roldán G L, Sola-Guirado R R, Agüera-Vega J, Castro-Garcia S. Analysis of fruit and oil quantity and quality distribution in high-density olive trees in order to improve the mechanical harvesting process. Spanish Journal of Agricultural Research, 2015; 13(2): 1-8.

[20] Pastor M, Humanes-Guillén J. In Poda del olivo moderna Olivicultura 
(5th ed.), 2006; pp.77-127, Editorial agrícola española. Madrid, Spain.

[21] Du X Q, Wu C Y, He L Y, Tong J H. Dynamic characteristics of dwarf Chinese hickory trees under impact excitations for mechanical fruit harvesting. Int J Agric \& Biol Eng, 2015; 8(1): 17-25.

[22] Ferguson L, Rosa U A, Castro-Garcia S, Lee S M, Guinard J X, Burns J, et al. Mechanical harvesting of California table and oil olives. Advances in Horticultural Science, 2010; 24(1): 53-63.

[23] Burns J K, Buker Iii R S, Roka F M. Mechanical harvesting capacity in sweet orange is increased with an abscission agent. HortTechnology, 2005; 15(4): 758-765.

[24] Roka F M, Ehsani R J, Futch S H, Hyman B R. Citrus mechanical harvesting systems - Continuous canopy shakers. Florida: Food and Economic Resources Department 2014; UF/IFAS Extension.
[25] Ferguson L, Castro Garcia S. Transformation of an Ancient Crop: Preparing California 'Manzanillo' Table Olives for Mechanical Harvesting. HortTechnology, 2014; 24(3): 274-280.

[26] Dias A, Peca J, Pinheiro A. Long-term evaluation of the influence of mechanical pruning on olive growing. Agronomy Journal, 2012; 104(1): 22-25.

[27] Blanco-Roldan G L, Gil-Ribes J A, Kouraba K, Castro-García S. Effects of trunk shaker duration and repetitions on removal efficacy for the harvesting of oil olives. Applied Engineering in Agriculture, 2009; 25(3): 329-334. pp 1-8

[28] Castillo-Ruiz F J, Pérez-Ruiz M, Blanco-Roldán G L, Gil-Ribes J A, Agüera J. Development of a telemetry and yield-mapping system of olive harvester. Sensors, 2015; 15(2): 4001-4018. 